\title{
Partial Ownership for a Public Firm and Corporate Social Responsibility
}

\author{
Lihua Han \\ School of Political Science and Public Administration, Shandong University, Qingdao, China \\ Email: lihuah@sdu.edu.cn
}

How to cite this paper: Han, L.H. (2019) Partial Ownership for a Public Firm and Corporate Social Responsibility. Theoretical Economics Letters, 9, 2447-2455. https://doi.org/10.4236/tel.2019.97155

Received: July 24, 2019

Accepted: September 27, 2019

Published: September 30, 2019

Copyright $\odot 2019$ by author(s) and Scientific Research Publishing Inc. This work is licensed under the Creative Commons Attribution International License (CC BY 4.0).

http://creativecommons.org/licenses/by/4.0/

\begin{abstract}
This paper introduces corporate social responsibility (CSR) into a traditional mixed oligopoly to examine effects of firms' CSR activities on privatization of a public firm. Private CSR firms take both profits and consumer surplus into consideration. It is shown that the optimal degree of privatization (nationalization) decreases (increases) with an increase in the percentage of consumer surplus taken into account by the CSR firms. In other words, the government should hold more shares in the partially privatized firm when the private firms are CSR rather than pure profit-maximizing ones. Furthermore, we find that it is socially optimal that the CSR firms partly (not totally) consider consumers' benefits.
\end{abstract}

\section{Keywords}

Partial Privatization, Corporate Social Responsibility, Mixed Oligopoly

\section{Introduction}

One of the issues analyzed by literature on mixed oligopoly is the decision by governments on whether to partially privatize their public firms. This literature on mixed oligopoly usually assumes that private shareholders maximize their own profits, which neglects the Corporate Social Responsibility (CSR). However, articles on firms' CSR activities have become increasingly popular in recent years (see, e. g., Gathak and Besley [1]; Siegel and Vitalino [2]; Baron [3]; Benabou and Tirole [4]; Kopel and Brand [5]; Kitzmueller and Shimshack [6]; Chang et al. [7]; Schmitz and Schrader [8]; Crifo and Forfet [9]; Lambertini et al. [10]). In this paper, we make an attempt to introduce an aspect of CSR into mixed oligopoly, wherein private firms interact with public firms, to examine the impacts of firms' CSR behaviors on privatization policies of a government.

Recently, much literature has developed, which examines strategic interaction 
between public and private firms. De Fraja and Delbono [11] analyze whether to privatize publicly-owned firms in a mixed oligopoly, in which public shareholders pursue maximization of social welfare while private shareholders maximize their own profits. One of their findings is that in a Cournot game the existence of a public firm may improve the social welfare because the public firms produce more, which leads to an increase in the market total output and a decrease in the market price. However, De Fraja and Delbono [11] only consider the case in which a public firm is owned completely by a government; thus, they ignore the possibility of a firm owned partially by a government. Fershtman [12] considers this possibility and analyzes the situation of a firm owned jointly by the private and public sectors. He shows that a partly nationalized firm might realize higher profits than its private, profit-maximizing competitor. Matsumura [13] also considers the possibility of partial privatization and finds that neither full nationalization nor full privatization is optimal. The government should own a part of (not all) shares of the privatized firm. Like Matsumura [13] points out that a government may be able to indirectly control the activities of the privatized firm by controlling the proportion of its shares held by the government. Thus, it is important that how many shares the government should hold in the privatized firm. Other existing studies on mixed oligopoly offer useful insight to understand a variety of issues related to partial privatization (see, e.g., Lee and Hwang [14]; Chang [15]; Chao and Yu [16]; Han [17]; Jain and Pal [18]; Ou et al. [19]). However, the issue of partial privatization with firms' CSR behaviors has received litter attention so far. The present paper introduces firms' CSR activities into Matsumura [13] to demonstrate the effects of firms' CSR behaviors on the optimal degree of privatization (nationalization). When a private firm is a CSR one, its objective is no longer pure profit-maximization. Such as Goering [20] and Wang et al. [21], a CSR firm considers not only its own profit but also consumer benefits, which is obviously different from the traditional mixed oligopoly. In this case, is partial privatization still optimal? Can the optimal degree of privatization be changed? Our analysis shows that the optimal degree of privatization decreases with the firms' CSR activities.

The remainder of this paper is organized as follows. Section 2 presents the model and describes the methodology of the analysis. Outcomes are derived in Section 3 and Section 4 concludes the paper.

\section{Model}

We consider an oligopoly market with a homogeneous good, served by $n$ private firms and a semi-public firm that jointly owned by the public and private sectors. The semi-public firm is indexed by firm 0 and a private firm is indexed by firm $i$ $(i=1, \cdots, n)$. All firms have identical technologies and the cost function of a firm is $C(q)=F+q^{2} / 2$, where $F$ denotes fixed costs. We assume $F=0$ with no loss of generality, since entry decisions are not considered. The inverse market demand is given by $p=a-Q$, where $p$ denotes the market price, $a$ is a positive 
parameter and $Q$ represents total output produced by all firms. $Q=q_{0}+\sum_{i=1}^{n} q_{i}$, where $q_{0}$ expresses the output of firm 0 and $q_{i}(i=1, \cdots, n)$ is the output of firm $i$. Thus, the profit of firm 0 is $\pi_{0}=(a-Q) q_{0}-q_{0}^{2} / 2$, and the profit of firm $i$ is

$$
\pi_{i}=(a-Q) q_{i}-q_{i}^{2} / 2 .
$$

Following Goering [20], we define firm is objective function as

$$
V_{i}=\pi_{i}+\alpha C S,
$$

where $C S$ denotes consumer surplus and $\alpha \in[0,1]$ is the percentage of the consumer surplus (indicates the weight of social responsibility in the objective function of each private firm). If the entire captured by firm is stakeholders $\alpha=1$ and, conversely, if none is captured $\alpha=0$. From $p=a-Q$, we obtain $C S=Q^{2} / 2$.

Like many other articles on partial privatization, we define the objective function of firm 0 as the weight average of goals of both the private investors and the government

$$
V_{0}=\theta\left(\pi_{0}+\alpha C S\right)+(1-\theta) W,
$$

where $\theta \in[0,1]$ is the share associated with the private investors. $\theta$ and $(1-\theta)$ can be interpreted as the shares controlled by private investors and the government. $\theta=0$ means that firm 0 is a complete public firm and it maximizes the social welfare while $\theta=1$ means that firm 0 is a complete private firm with CSR. Here, the social welfare comprises the consumer surplus and the producer surplus. As usual, the producer surplus is the profits of all firms. Thus, the social welfare function can be expressed as

$$
W=C S+\pi_{0}+\sum_{i=1}^{n} \pi_{i} .
$$

We consider a two-stage game. In stage 1, the government maximizes Equation (4) to determines the degree of privatization, $\theta$. In stage 2 , the firms observe $\theta$ and then simultaneously and independently choose their output levels. Firm $i$ maximizes Equation (2) and firm 0 maximizes Equation (3). To obtain the sub-game perfect Nash equilibrium, we solve the game by standard backward induction method.

\section{Equilibrium and Outcomes}

Given $\alpha, \theta$ and $q_{0}$, the objective function of firm $i$ is maximized at

$$
q_{i}=\left(a-q_{0}+\alpha q_{0}\right) /(2+n-n \alpha),
$$

which is the reaction of firm $i$. Similarly, we induce the reaction function of firm 0

$$
q_{0}=\left(a-n q_{i}+n \alpha \theta q_{i}\right) /(2+\theta-\alpha \theta) .
$$

Solving Equation (5) and Equation (6) simultaneously, we obtain the second-stage equilibrium outcomes as follows:

$$
q_{0}=a(2-n \alpha+n \alpha \theta) / \Delta, \quad q_{i}=a(1+\alpha+\theta-\alpha \theta) / \Delta,
$$




$$
Q=a(2+n+n \theta) / \Delta, \quad p=[2+2 \theta(1-\alpha)-n \alpha(1+\theta)] / \Delta,
$$

where $\Delta=(1-\alpha)(n+2 \theta+n \theta)+4$. Differentiation of Equation (7) and Equation (8) with respect to $\alpha$ yields the following:

$$
\begin{gathered}
\partial q_{0} / \partial \alpha=a\left[n^{2}(\theta+1)(\theta-1)+2 n\left(\theta^{2}+2 \theta-1\right)+4 \theta\right] / \Delta^{2}, \\
\partial q_{i} / \partial \alpha=2 a(n+n \theta+2) / \Delta^{2}>0, \\
\partial Q / \partial \alpha=a(n+2 \theta+n \theta)(n+n \theta+2) / \Delta^{2}>0, \\
\partial p / \partial \alpha=-a\left[n(n+2)(\theta+1)^{2}+4 \theta\right] / \Delta^{2}<0 .
\end{gathered}
$$

From the above expressions, we see that with an increase in $\alpha$, the outputs of the private firms and the total market output increase whereas the market price decreases. $\partial q_{0} / \partial \alpha>0$ if $\theta=1, \partial q_{0} / \partial \alpha<0$ if $\theta=0$. Comparative statics results with respect to $\theta$ yield

$$
\begin{gathered}
\partial q_{0} / \partial \theta=2 a\left[n^{2} \alpha(1-\alpha)-n\left(1-4 \alpha+\alpha^{2}\right)-2(1-\alpha)\right] / \Delta^{2} \\
\partial q_{i} / \partial \theta=2 a(1-\alpha)(1-\alpha-n \alpha) / \Delta^{2}
\end{gathered}
$$

Lemma 1. Privatization increases the output of firm 0 whereas it decreases the output of firm $i$ if $\alpha>1 /(n+1)$.

In order to interpret the effect of privatization on the firms' outputs, we depict individually the reaction curves of firm 0 and firm $i$ when $\alpha$ is sufficiently small and large in Figure 1 and Figure 2 according to Equation (5) and Equation (6). In Figure 1 and Figure 2, $R_{0}\left(R_{i}\right)$ and $R_{0}^{\prime}\left(R_{i}^{\prime}\right)$ are the reaction curves of firm 0 (firm $i$ ). As $\theta$ increases, the reaction curve of firm 0 shifts from $R_{0}$ to $R_{0}^{\prime}$ and the reaction curve of firm $i$ shifts from $R_{i}$ to $R_{i}^{\prime}$. From Figure 1 and Figure 2, we observe that the output of firm 0 declines while the output of firm $i$ raise with an increase of $\theta$ when $\alpha$ is sufficiently small. On the contrary, the output of firm 0 increases and the output of firm $i$ decreases with an increase of $\theta$.

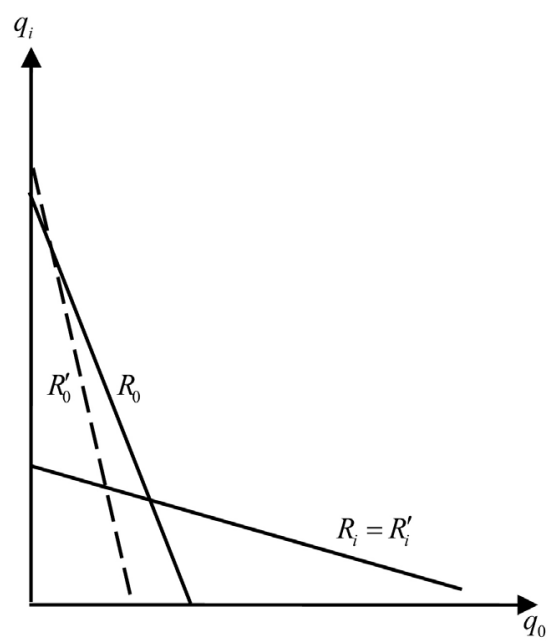

Figure 1. $\alpha$ is sufficiently small. 


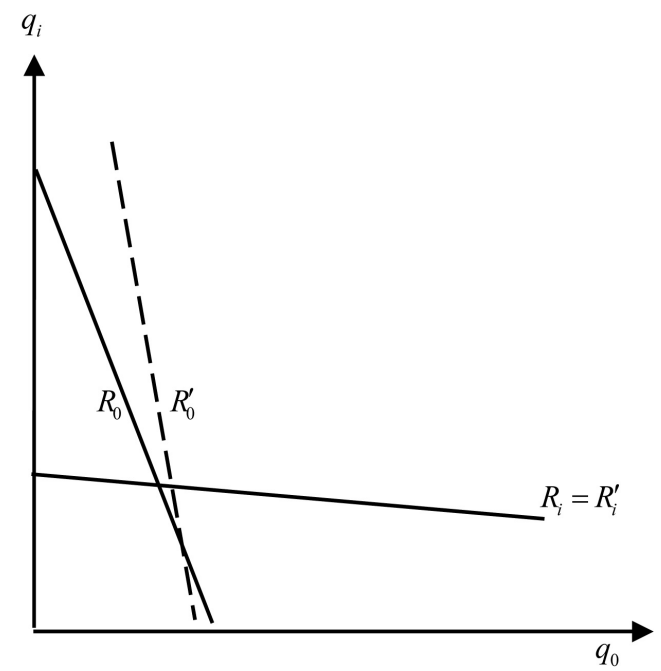

Figure 2. $\alpha$ is sufficiently large.

Lemma 1 indicates that the effect of privatization is different from that in the model of traditional mixed oligopoly derived in Matsumura [13], which show that privatization always decreases the output of the public firm and increases the output of the private firms.

Differentiation of $Q$ and $p$ with respect to $\theta$ yields

$$
\begin{gathered}
\partial Q / \partial \theta=4 a(n \alpha+\alpha-1) / \Delta^{2}, \\
\partial p / \partial \theta=4 a(1-\alpha-n \alpha) / \Delta^{2} .
\end{gathered}
$$

Lemma 2. Privatization increases the total market output whereas it decreases the market price if $\alpha>1 /(n+1)$.

The intuition behind Lemma 2 is obvious. When $\alpha$ is sufficiently large, the benefits of consumers are paid much attention by the private firms, which results in an increase in the market total outputs and a decrease in the market price.

Using Equation (7) and Equation (8), we get the profits of each firm and consumer surplus as follows:

$$
\begin{gathered}
\pi_{0}=a^{2}[2+4 \theta(1-\alpha)-n \alpha(1+3 \theta)][2-n \alpha(1-\theta)] / 2 \Delta^{2}, \\
\pi_{i}=a^{2}(1+\alpha+\theta-\alpha \theta)[(1+\theta)(3-2 n \alpha)-\alpha(1+3 \theta)] / 2 \Delta^{2}, \\
C S=a^{2}(2+n+n \theta)^{2} / 2 \Delta^{2} .
\end{gathered}
$$

Comparative statics results show that an increase in $\alpha$ increases the consumer surplus but its effect on each firm's profit is ambiguous, the profits of firms either rise or fall depending on the values $\alpha, \theta$ and $n$ (the exact expressions presented in the Appendix). Similarly, we find that the effect of privatization on the profits of the firms and the consumer surplus are ambiguous.

Substitution of Equations (17)-(19) into (4) yields the following

$$
W=a^{2}\left\{n\left(1+n+n \theta^{2}\right)\left(1-2 \alpha-\alpha^{2}\right)+\theta(1-\alpha)[2 n(5+n-\alpha-n \alpha)+(8+3 n \theta+n \alpha \theta)]+2(4+3 n)\right\} / 2 \Delta^{2}
$$


The following proposition can be derived from Equation (20).

Proposition 1. The optimal degree of privatization (nationalization) decreases (increases) with an increase in $\alpha$.

Proof:

The differentiation of $W$ with respect to $\theta$ yields

$$
\partial W / \partial \theta=-2 a^{2}(1-\alpha-n \alpha)^{2}[n(1-\alpha)(1-\theta)+4 \theta] / \Delta^{3} .
$$

Let $\partial W / \partial \theta=0$, we get the optimal degree of privatization:

$$
\theta^{*}=n(1-\alpha) /[n(1-\alpha)+4] \text {. }
$$

The derivative of $\theta^{*}$ with respect to $\alpha$ is

$$
\partial \theta^{*} / \partial \alpha=-4 n /(n-n \alpha+4)^{2}<0 .
$$

The intuition behind proposition 1 is as follows. The sum of the consumer surplus and the producer surplus is biggest at the optimal degree of privatization (nationalization). With an increase in $\alpha$, the consumer surplus increases but the market price declines, which leads to the profits of the firms (producer surplus) fall. To avoid too much decrease in producer surplus, the government reduces (raises) the degree of privatization (nationalization).

The differentiation of $W$ with respect to $\alpha$ yields

$$
\partial W / \partial \alpha=2 a^{2}(1-\alpha-n \alpha)(2+n+n \theta)\left(n+2 \theta^{2}+n \theta^{2}\right) / \Delta^{3} .
$$

Let $\partial W / \partial \alpha=0$, we obtain the optimal $\alpha^{*}$ :

$$
\alpha^{*}=1 /(n+1) \text {. }
$$

The derivative of $\alpha^{*}$ with respect to $n$ is

$$
\partial \alpha^{*} / \partial n=-1 /(n+1)^{2} \text {. }
$$

We summary the above results in Proposition 2.

Proposition 2. The optimal $\alpha^{*}$ is in an interval $(0,1)$ and the optimal $\alpha^{*}$ decreases with an increase in the number of firms.

Proposition 2 indicates that it is not socially optimal that the private firms do not take the consumers' benefits into account at all. Meanwhile, it is not socially optimal that the private firms consider too much the consumers' benefits. The private firms produce too small when they seek the maximization of their own profits $(\alpha=0)$ whereas the private firms produce too much when the private firms completely take consumers' benefits into the objective functions ( $\alpha=1)$. Thus, $0<\alpha<1$ is optimal. Furthermore, the optimal $\alpha^{*}$ falls as the number of firms increases because the total market output rises with the increase in the number of the firms.

\section{Concluding Remarks}

The conventional economic literature adopts the profit-maximization hypothesis in the analysis of the behavior of private firms and overlooks firms' CSR activities. The present paper extends mixed oligopoly to considering an aspect of 
corporate social responsibility (CSR) into firms' objective function. In our model, the private firms with CSR activities interact with the partially privatized firm. Following Goering [20], the CSR firms are assumed to maximize the weighted sum of profit and consumer surplus. Meanwhile, a partially privatized firm cares about both its own profits and social welfare, which is widely adopted in the literature on mixed oligopoly (see Matsumura [13]). Our finding is interesting and shows that the government should hold more shares in the partially privatized firm with the private firms' CSR activities.

One possible extension of the paper would be investigating an international market with a foreign firm. How would a foreign form with a CSR motive affect privatization policies? Extending our formulation to concerning a foreign competitor is a further subject for future research.

\section{Acknowledgements}

Lihua Han thanks a financial support from the national social science foundation of China (No. 14BJL114).

\section{Conflicts of Interest}

The author declares no conflicts of interest regarding the publication of this paper.

\section{References}

[1] Gathak, M. and Besley, T. (2007) Retailing Public Goods: The Economics of Corporate Social Responsibility. Journal of Public Economics, 91, 1645-1663. https://doi.org/10.1016/j.jpubeco.2007.07.006

[2] Siegel, D.S. and Vitalino, D.F. (2007) An Empirical Analysis of the Strategic Use of Corporate Social Responsibility. Journal of Economics and Management Strategy, 16, 773-792. https://doi.org/10.1111/j.1530-9134.2007.00157.x

[3] Baron, D. (2008) Managerial Contracting and Corporate Social Responsibility. Journal of Public Economics, 92, 262-288.

https://doi.org/10.1016/j.jpubeco.2007.05.008

[4] Benabou, R. and Tirole, J. (2010) Individual and Corporate Social Responsibility. Economica, 77, 1-19. https://doi.org/10.1111/j.1468-0335.2009.00843.x

[5] Kopel, M. and Brand, B. (2012) Social Responsible Firms and Endogenous Choice of Strategic Incentives. Economic Modelling, 29, 982-989.

https://doi.org/10.1016/j.econmod.2012.02.008

[6] Kitzmueller, M. and Shimshack, J. (2012) Economic Perspectives on Corporate Social Responsibility. Journal of Economic Literature, 50, 51-84.

https://doi.org/10.1257/jel.50.1.51

[7] Chang, Y., Chen, H., Wang, L.F.S. and Wu, S. (2014) Corporate Social Responsibility and International Competition: A Welfare Analysis. Review of International Economics, 22, 625-638. https://doi.org/10.1111/roie.12117

[8] Schmitz, J. and Schrader, J. (2015) Corporate Social Responsibility: A Microeconomic Review of the Literature. Journal of Economic Surveys, 29, 27-45.

https://doi.org/10.1111/joes.12043 
[9] Crifo, P. and Forfet, V.D. (2015) The Economics of Corporate Social Responsibility: A Firm Level Perspective Survey. Journal of Economic Surveys, 29, 112-130. https://doi.org/10.1111/joes.12055

[10] Lambertini, L., Palestini, A. and Tampieri, A. (2016) CSR in an Asymmetric Duopoly with Environmental Externality. Southern Economic Journal, 83, 236-252. https://doi.org/10.1002/soej.12140

[11] DeFraja, G. and Delbono, F. (1989) Alternative Strategies of a Public Enterprise in Oligopoly. Oxford Economic Papers, 41, 302-311. https://doi.org/10.1093/oxfordjournals.oep.a041896

[12] Fershtman, C. (1990) The Interdependence between Ownership Status and Market Structure: The Case of Privatization. Economica, 57, 319-328. https://doi.org/10.2307/2554937

[13] Matsumura, T. (1998) Partial Privatization in Mixed Duopoly. Journal of Public Economics, 70, 473-483. https://doi.org/10.1016/S0047-2727(98)00051-6

[14] Lee, S.H. and Hwang, H.S. (2003) Partial Ownership for the Public Firm and Competition. Japanese Economic Review, 54, 324-335.

https://doi.org/10.1111/1468-5876.00261

[15] Chang, W.W. (2005) Optimal Trade and Privatization Policies in an International Duopoly with Cost Asymmetry. Journal of International Trade \& Economic Development, 14, 19-42. https://doi.org/10.1080/0963819042000333234

[16] Chao, C.C. and Yu, E.S.H. (2006) Partial Privatization, Foreign Competition, and Optimum Tariff. Review of International Economics, 14, 87-92. https://doi.org/10.1111/j.1467-9396.2006.00562.x

[17] Han, L. (2012) Strategic Privatization and Trade Policies in an International Mixed Oligopoly. The Manchester School, 80, 580-602. https://doi.org/10.1111/j.1467-9957.2011.02245.x

[18] Jain, R. and Pal, R. (2012) Mixed Duopoly, Cross-Ownership and Partial Privatization. Journal of Economics, 107, 45-70. https://doi.org/10.1007/s00712-011-0260-6

[19] Ou, R., Li, J., Lu, J. and Guo, C. (2016) The Optimal Privatization Policies under an International Mixed Duopoly. Review of Development Economics, 20, 228-238. https://doi.org/10.1111/rode.12207

[20] Goering, G.E. (2007) The Strategic Use of Managerial Incentives in a Non-Profit Firm Mixed Duopoly. Managerial and Decision Economics, 28, 83-91. https://doi.org/10.1002/mde.1307

[21] Wang, L.F.S., Wang, Y. and Zhao, L. (2012) Tariff Policy and Welfare in an International Duopoly with Consumer-Friendly Initiative. Bulletin of Economic Research, 64, 56-64. https://doi.org/10.1111/j.1467-8586.2010.00382.x 


\section{Appendix}

$$
\begin{gathered}
\partial \pi_{0} / \partial \alpha=a^{2}(n+n \theta+2)\left[n^{2} \alpha(1+3 \theta)(1-\theta)-2 n\left(1+2 \theta-\theta^{2}-2 \alpha \theta+4 \alpha \theta^{2}\right)-4 \theta(1-\theta+\alpha \theta)\right] / \Delta^{3} \\
\partial \pi_{i} / \partial \alpha=a^{2}(n+n \theta+2)\left[2(1+\theta)(1-\theta)-2 \alpha\left(1+2 \theta-\theta^{2}\right)-n(1+\theta)(1+\theta-\alpha \theta+3 \alpha)\right] / \Delta^{3} \\
\partial C S / \partial \alpha=a^{2}(n+2 \theta+n \theta)(n+n \theta+2)^{2} / \Delta^{3}>0 \\
\partial \pi_{0} / \partial \theta=4 a^{2}(1-\alpha-n \alpha)\left[n^{2} \alpha \theta(1-\alpha)-n \alpha(1-5 \theta+\alpha \theta)-n \theta+2(1-\theta+\alpha \theta)\right] / \Delta^{3} \\
\partial \pi_{i} / \partial \theta=2 a^{2}(1-\alpha-n \alpha)\left[\alpha^{2}(n+1)(\theta+1)-\alpha(n+4 \theta+n \theta)+3(1+\theta)\right] / \Delta^{3} \\
\partial C S / \partial \theta=4 a^{2}(\alpha+n \alpha-1)(n+n \theta+2) / \Delta^{3}
\end{gathered}
$$

